\title{
ALGUNOS FACTORES A CONSIDERAR EN EL ANÁLISIS DE UN GENOCIDIO LATINOAMERICANO: EL PAPEL DE LOS ESTADOS UNIDOS, COLONIALISMO INTERNO, LEGADOS DE SILENCIOS SOCIALES
}

\author{
MARCIA ESPARZA (CUNY) \\ Directora Proyecto de Memoria Histórica (HMP) \\ John Jay College of Criminal Justice \\ City University of New York \\ Nueva York, Estados Unidos de América \\ mesparza@jijay.cuny.edu
}

\begin{abstract}
Resumen
En este breve ensayo intento identificar tres factores que en mi opinión deben considerarse a la hora del análisis de procesos genocidas en la región: el papel que juegan los proyectos imperiales de los Estados Unidos, particularmente, pero también Francia y sus doctrinas de la seguridad y desarrollo nacional; el colonialismo interno que afecta a sectores importantes de la población, grupos subalternos que viven en situación de miseria y explotación y que son a la vez víctimas y usados como carne de cañón, tal como la población indígena; y los legados ideológicos del anticomunismo que reproducen la mitología de la Guerra Fría, tales como la "teoría de los dos demonios" o del "enemigo interno".
\end{abstract}

Palabras clave:

Seguridad Nacional de los EEUU - Colonialismo Interno - Genocidio - Legados Latinoamérica

\begin{abstract}
In this brief essay, I hope to identify three factors that in my opinion need to be considered when examining genocidal processes in the Latin American context: the role played by the United States Imperial projects, particularly, but also France and their doctrines of national security; the internal colonialism affecting subaltern groups who live in conditions of misery and exploitation and who are also victims used as cannon fodders, such as the indigenous population; and the ideological anticommunist legacy reproducing the mythology of the Cold War such as the "demon theory" and the "internal enemy".
\end{abstract}

\section{Keywords:}

National Security - Internal Colonialism - Genocide - Legacies - Latin America 


\title{
ALGUNOS FACTORES A CONSIDERAR EN EL ANÁLISIS DE UN GENOCIDIO LATINOAMERICANO: EL PAPEL DE LOS ESTADOS UNIDOS, COLONIALISMO INTERNO, LEGADOS DE SILENCIOS SOCIALES
}

\author{
MARCIA ESPARZA (CUNY)
}

mesparza@,jiav.cuny.edu

Aunque escasos hasta hace muy poco tiempo, los estudios que examinan las dictaduras y guerras en Latinoamérica a través del prisma de procesos genocidas son de gran trascendencia para comprender los crímenes de estado de los ejércitos locales, entrenados muchas veces en Estados Unidos, para eliminar la columna vertebral de la militancia obrera, indígena y campesina. ${ }^{1}$ En este sentido, los trabajos interdisciplinarios desde la historia, la antropología y la sociología en Argentina, Chile, Colombia y Guatemala ${ }^{2}$ han comenzado a llenar importantes y complejas lagunas teóricas y empíricas para comprender las particularidades, lafunción social y el legado de la violencia estatal extrema. ${ }^{3}$ Como sugiero en Violencia de Estado y Genocidio en Latinoamérica, para el historiador Norteamericano Henry R. Huttenbach, fundador de la Revista de Genocidio y Profesor Emérito de City University of New York (CUNY) esta discusión es relevante porque sin investigar las formas extremas de violencia en Latinoamérica los estudios de genocidio son incompletos. Para Huttenbach mientras no se incluyan más ejemplos dentro de la universalidad de casos de genocidio, es prematuro proclamar una teoría general del fenómeno que identifique patrones comunes y distintos. ${ }^{4}$

\footnotetext{
1 García Ferreira, Roberto (comp.), Guatemala y la Guerra Fría en América Latina 1947-1977, Centro de Estudios Urbanos y Regionales de Universidad de San Carlos, Guatemala, 2010. Según la historiadora mexicana Maribel Vasconcelos, "La administración de Kennedy planteó su política exterior a través de formulaciones como: la nueva frontera, la respuesta flexible y la Alianza para el Progreso (AID). La AID se trataba de un plan a diez años de duración que tendría que servir en América Latina como el Plan Marshall había funcionado en Europa. Para llevarlo a la práctica, Estados Unidos realizó un donativo de mil millones de dólares, con el objetivo de satisfacer las necesidades apremiantes de los pueblos americanos en lo referente a viviendas, trabajo, tierra, salud y escuelas". Ver Vasconcelos, Maribel, La Guerra Fría, Tesis de Maestría, Instituto de Investigaciones Dr. José María Luis Mora, 2012, pág.19; Cockcroft, James, América Latina y Estados Unidos, México, Siglo XXI, 1996; Joseph, Gilbert M. (ed.), In from the Cold, Latin America's New Encounter with the Cold War, Durham, Duke University Press, 2007; Spenser, Daniela (comp.), Espejos de la guerra fría, México, CIESAS-Porrúa, 2004.

2 Cf. por ejemplo Águila, Gabriela, Dictadura, represión y sociedad en Rosario, 1976-1983: Un estudio sobre la represión y los comportamientos y actitudes sociales en dictadura. Buenos Aires, Prometeo, 2008; Esparza, Marcia; Huttenbach, Henry y Feierstein, Daniel (eds.), State Violence and Genocide in Latin America. London, Routledge: Critical Terrorism Studies, 2010; Feierstein, Daniel, Seis Estudios sobre Genocidio. Análisis de relaciones sociales: otredad, exclusión, exterminio. Buenos Aires, EUDEBA, 2000 y El genocidio como práctica social. Entre el nażismo y la experiencia argentina. Buenos Aires, Fondo de Cultura Económica, 2007; Gómez-Suárez, Andrei, "US-Colombian relations in the 1980s: political violence and the onset of the Unión Patriótica genocide", en Esparza, Marcia et al., State Violence and Genocide in Latin America, op. cit.; Pereira, Víctor, Unfinished Conquest: the Guatemalan Tragedy. California, University of California Press, 1993; y Salvi, Valentina, "De Vencedores a víctimas: 25 años de memoria castrense", en Temas y Debates No 17, Rosario, 2009.

${ }^{3}$ Entre mediados de la década de1940 hasta principios de los años noventa.

${ }^{4}$ Ver Huttenbach, Henry, Journal of Genocide Research, 6, 2, June 2004. Para comprender estos procesos, claro está, en primer lugar es importante preguntarse, ¿qué es un genocidio? Daniel Fieierstein sugiere que refiere a los crímenes de estado enmarcados dentro de una ideología que busca la reorganización social. Este enfoque ayuda a comprender la extrema polarización étnica, racial y de clase de la región, característica de otras sociedades que han sufrido el
} 
En este breve ensayo intento identificar tres factores que en mi opinión deben considerarse a la hora del análisis de procesos genocidas en la región: el papel que juegan los proyectos imperiales de los Estados Unidos, ${ }^{5}$ particularmente, pero también Francia y sus doctrinas de la seguridad y desarrollo nacional; el colonialismo interno que afecta a sectores importantes de la población, grupos subalternos ${ }^{6}$ que viven en situación de miseria y explotación y que son a la vez víctimas y usados como carne de cañón, tal como la población indígena; y los legados ideológicos del anticomunismo que reproducen la mitología de la Guerra Fría, tales como la "teoría de los dos demonios" o del "enemigo interno". ${ }^{7}$ A pesar de las diferencias regionales entre Centroamérica y el Cono Sur, considero que sus respectivas historias locales, aunque obviamente con sus particularidades, representan casos representativos por que estas están entrelazadas y marcadas por el papel hegemónico de los Estados Unidos desde la implementación de la Doctrina Monroe de 1823, y por lo tanto, comparten una historia común entre ellas en las etapas coloniales, postcoloniales, Guerra Fría y post-Guerra Fría.

\section{Colonalismo interno}

El colonialismo interno que afecta a las comunidades más vulnerables, la población indígena y afro-descendiente, es escasamente considerado un factor a tomar en cuenta a la hora de investigar las ideologías que facilitan la violencia de estado en la región. Este tipo de sistema político, económico y social, marcado por el clasismo y el racismo virulento, es uno de los contextos locales de explotación que aún permanecen en Latinoamérica. ${ }^{8}$ Sin embargo, pocos son los estudios que analizan la continuidad de ideologías creadas y articuladas por procesos coloniales y de explotación doméstica. Pocos textos se preguntan cuándo y cómo y si ha sido posible desmantelar valores y creencias racistas, herencia de la colonización europea. Pocos trabajos sociológicos, por ejemplo, toman como punto de referencia el rígido orden vertical organizado por la colonia sobre la población originaria, sustentado en nociones que definían quien era "humano" o "civilizado".

Esta otredad tenía como fin legitimar su dominación sobre los territorios conquistados en el hemisferio. La colonización impuso una estructura de dominación basada en castas sociales que

exterminio masivo de sus poblaciones. Es importante además señalar que, por la mayor parte, la violencia de estado en contra de grupos que reclaman reivindicaciones políticas, de clase, son excluidos dentro del paradigma global de genocidios. Ya la literatura concluye que este vacío de estudios en Latinoamérica en parte se debe a que la Convención de la ONU excluye grupos políticos, y por lo tanto los grupos de izquierda, comunistas, socialistas, de centro-izquierda perseguidos, torturados, asesinados, masacrados y abusados sexualmente, no califica. Harff y Gurr han usado el término politicidio para referirse al asesinato de oponentes políticos. La mayor parte de académicos dice que un grupo victimizado debe poseer características estables, como la etnicidad o la nacionalidad, que puedan diferenciarlos con facilidad de otros grupos nacionales. Según este argumento, a diferencia de los indicadores de ideología política, los identificadores de raza y etnia constituyen identidades inmutables que delimitan al grupo victimizado, despojándolos de la posibilidad de escapar a ser vistos como el "otro".

${ }^{5}$ Hobsbawm, Eric, The Age of Empire (1875-1914). New York, Vintage Group, 1989.

${ }^{6}$ Spivak, Gayatri, In Other Worlds: Essays in Cultural Politics. New York, Methuen, 1987.

${ }^{7}$ Aunque no hay espacio para la discusión en este ensayo, en mi trabajo señalo como las Operaciones de Guerra Psicológica (OPSYC) contrainsurgente de la Guerra Fría (con entrenamiento de los Estados Unidos y Francia con su experiencia en Indochina y en Argelia) se basaron en propaganda para manipular a la población en Argentina, Chile, Colombia y Guatemala.

${ }^{8}$ Cf. González Casanova, Pablo, “Colonialismo Interno, Una Redefinición”, en Borón, Atilio (comp.), La teoría marxista boy: problemas y perspectivas. Buenos Aires, CLACSO, 2006, en línea en http://biblioteca.clacso.edu.ar/ar/libros/campus/marxis/P4C2Casanova.pdf, consulta 6 de marzo de 2013; Quijano, Alberto, "The Coloniality of Power, Eurocentrism and LatinAmerica, en Neplanta", Views from South 1. 3., Duke University Press, 2000, en línea en http://www.unc.edu/ aescobar/wan/wanquijano.pdf, consulta 6 de marzo de 2013; y Young, Robert C. J., Postcolonialism: An Historical Introduction. Oxford, Blackwell Publishers, 2001, sobre el colonialismo interno que impacta en las sociedades en Latinoamérica, en palabras de Young: "Donde el dominio colonial fue reemplazado por los herederos de la autocracia de los conquistadores europeos", pág. 20. En los EEUU la noción de colonialismo interno hace referencia a la subordinación de los chicanos. 
construyó, primero y ante todo, al sujeto indígena, considerado una raza inferior, ${ }^{9}$ como el grupo social "externo". Según Walter Mignolo, la construcción del imaginario geopolítico occidental requirió de la diferenciación de grupos sociales para justificar la exclusión a grupos originarios que rehusaban reducirse a reservas indígenas (las encomiendas) cuyo trabajo era explotado a beneficio de las metrópolis, mientras algunos grupos se resistían la subordinación a la que se les forzaba por medio de atrocidades y trabajo forzado para la Corona. ${ }^{10}$

Dentro de este esquema, los grupos indígenas quedarían marcados socialmente como grupos "menos humanos". Considerados salvajes, razas inferiores, por los criollos (los descendientes de los españoles), los pueblos originarios fueron presa fácil de las políticas de exterminio y de cristianización, como sugiere Tzvetan Todorov. ${ }^{11}$

Para los académicos que consideramos el postcolonialismo y el colonialismo interno como ejes claves en la construcción de la otredad en Latinoamérica, la emancipación política de España en el siglo XIX hizo poco por desmantelar la ideología y estructuras colonialistas que polarizaron política y económicamente a las nuevas naciones. La emancipación de España no condujo a una verdadera independencia económica y política. ${ }^{12}$

Para el mexicano Leopoldo Zea, el mayor problema lo constituyó el hecho de que las costumbres sociales y prácticas políticas de los colonizadores permanecieron intactas en la mente de las élites y de los ejércitos coloniales. ${ }^{13}$ Incapaces de liberarse de la herencia colonial y de transformar su mentalidad colonial, las clases burguesas dominantes, que se representan a sí mismas como "europeas", de tez blanca, han repetido y perpetuado sistemas de exclusión contra los grupos marginados. Estos son considerados "rebeldes" al momento de organizarse y reclamar la justa distribución de las grandes riquezas naturales del continente.

Desde la independencia a principios del siglo XIX, según Esteban Echeverría, a los ojos de las élites los grupos sociales considerados como inferiores fueron percibidos como carentes de cultura cívica, lo que justificaba invocar "la mano dura", un eufemismo usado por regímenes autoritarios a fin de disciplinarlos como fuerza de trabajo obediente, al servicio de la explotación capitalista. Para muchas comunidades indígenas en Argentina, Chile y Guatemala, este contexto de explotación se tradujo en un verdadero colonialismo interno, mantenido por parte de las élites ha seguido reforzando patrones de exclusión social a través del caudillismo y la tiranía, y la perpetuación de poderes militares y eclesiásticos serviles a la oligarquía. Hasta hoy, la oligarquía post-colonial, las élites transnacionales y sectores de la Iglesia conservadora, siguen ejerciendo control sobre las clases bajas de piel oscura, más implacablemente que antes, reforzando aún más la herencia colonial. En mi investigación sobre la post-Guerra Fría en Guatemala, sugiero que el

\footnotetext{
${ }^{9}$ Zea, Leopoldo, América como conciencia. México, UNAM, 1972

${ }^{10}$ En Chile y en Argentina, hasta el día de hoy los mapuches se organizan y movilizan para recuperar las tierras usurpadas por los conquistadores. Más recientemente, continuando con la lógica colonial, hay un despojo de las tierras indígenas que va desde las respectivas "conquistas al desierto" del siglo XIX, hasta la compra o adquisición por distintos medios de tierras indígenas por multinacionales y extranjeros en las últimas décadas. Agradezco a Gabriela Águila por esta observación.

${ }^{11}$ Todorov, Tzvetan, La Conquista de América: la Cuestion del Otro (Conquest of America: the Question of the Other). 1984.

12 Cf. Mariátegui, José Carlos, Siete ensayos de interpretación de la realidad peruana. Caracas, Fundación Biblioteca Ayacucho, 2007; González Casanova, Pablo, “Colonialismo Interno, Una Redefinición”, op. cit.; Quijano, Alberto, "The Coloniality of Power,...", op. cit. Las ocupaciones militares en el Caribe y Centroamérica añadieron otra capa de polarización económica, étnica y política a la región.

13 Zea argumenta que este colonialismo interno estaba gobernado por dos bandos: los que aspiraban a construir una sociedad modelo radicalmente diferente de la madre patria española, y aquellos que soñaban con copiar el régimen de los colonizadores. Sugiere que las hondas divisiones étnicas y de clase formadas durante el período colonial quedaron intactas en buena medida, en especial en áreas donde los conflictos indígenas por la tierra no fueron resueltos.
} 
proceso genocida reprodujo paradojas coloniales, de cooptación de líderes, "dividir y conquistar", y la violencia extrema en contra de grupos indígenas. ${ }^{14}$

Quienes esperaban derribar el legado económico, político y cultural del colonialismo europeo fueron testigos del arribo de la segunda ola colonizadora, esta vez "atados" a la mano dura de Estados Unidos. La formulación de la Doctrina Monroe en 1823 y luego del credo del Destino Manifiesto en 1893, cuyo objetivo era mantener la influencia económica de Europa lejos de las costas del continente, estableció y aseguró la presencia de Estados Unidos en el territorio.

\section{Papel de los Estados Unidos: ideología, agencias y pactos}

Con esta división de clase, étnico y racial colonial y postcolonial como telón de fondo, los esfuerzos de contención al comunismo realizados por EEUU durante el siglo XX tuvieron éxito con relativa facilidad, ya que estos fueron impuestos en sociedades profundamente polarizadas socio-económicamente. ${ }^{15}$

Según Zea la pugna ideológica entre el Este y el Oeste fue usada en buena medida como pretexto para dar solución a problemas sociales que estaban fuertemente enraizados en la polarización socio-económica que existía con anterioridad a la era anticomunista. Desde la década de 1950, movimientos populares que denunciaban la explotación que traen los modelos imperialistas a la región, irrumpieron en el paisaje político. Amplios movimientos sociales cuestionaban las graves condiciones económicas, producto de fallidas políticas de desarrollo nacionalista las que provocaron, irónicamente, una mayor dependencia con los Estados Unidos. James Cockcroft señala que para este tiempo, había más hambre en Latinoamérica que en India, Pakistán o Bangladesh. El triunfo de la revolución cubana, y las nuevas filosofías indígenas y de izquierda, en especial la teología de la liberación, alimentaron estos movimientos populares e insurgencias de izquierda, como fue el caso en Guatemala y en Chile. ${ }^{16}$

Para el sociólogo James Petras, la radicalización de la organización política suele asociarse al desarrollo económico. La introducción de modelos capitalistas de producción, argumenta Petras, ha fomentado "la concentración de trabajadores [que] por lo común han generado fuerzas sociales para la organización política radical de masas". De esta forma los espacios del movimiento obrero así abiertos, en ausencia de represión estatal, "se [convirtieron] en los

\footnotetext{
${ }^{14}$ En mis estudios de la post-Guerra Fría en Guatemala a través de la literatura de genocidio, de campesinos asalariados en Latinoamérica (Petras, James, Politics and Social Structure in Latin America, New York, Monthly Review Press, 1970) reexamino la "situación colonial" concepto clave dentro de los estudios postcoloniales analizada por la clásica trilogía comprendida por Aime de Cesaire (Discourse on Colonialism, New York, Monthly Review Press, 2000), Franz Fanon (Los Condenados de la Tierra, 2008) y Albert Memmi (The Colonizer and the Colonized. Boston, Beacon Press, 1991) Así, mantengo que la opresión de clase y étnica que facilita la cooptación de autoridades comunales que "negocian", desde la subordinación, con representantes de las instituciones del estado, principalmente con el ejército, que se representa a sí mismo y es a la vez recibido en el campo "como un amigo" o como "una piedra en el zapato", dependiendo de la historia de cada comunidad indígena del altiplano guatemalteco.

15 Leo Kuper enfatiza las condiciones necesarias para que un genocidio se ejecute: las sociedades más vulnerables a la violencia genocida son aquellas denominadas "pluralistas" en su forma más extrema (Genocide: Its Political Use in the Twentieth Century. New Haven, Yale University Press, 1981, págs.57-83) o con profundas fracturas internas, por lo general legado del colonialismo.

${ }^{16}$ Una segunda explicación para la escalada de violencia estatal se halla en el triunfo de la revolución cubana de 1959, que las élites y los Estados Unidos temían fuera precursora de una revolución latinoamericana a mayor escala. La supuesta amenaza de una "segunda Cuba" dio a Estados Unidos aún más justificación para proteger de la invasión soviética sus baluartes hegemónicos y económicos en el hemisferio. A la vez, los modelos nacionalistas y la reforma agraria impulsados por el presidente Arbenz de Guatemala, en 1951, y la elección del socialista Salvador Allende en Chile en 1970, fueron vistos por las élites y por Washington como algo intolerable y que desafiaban los intereses multinacionales, la Kenneth y Anaconda. Por ende, la amenaza del "efecto dominó" (si un país caía preso del comunismo, los demás le seguirían) se usó para justificar la ayuda militar estadounidense a los ejércitos latinoamericanos para la criminalización y eliminación de grupos populares.
} 
cimientos de movimientos revolucionarios en situaciones en las que tenían la posibilidad de comunicarse entre sí y organizarse". ${ }^{17}$ Este crecimiento de la clase trabajadora se vio acompañado por una expansión generalizada de los sindicatos. ${ }^{18}$

En este contexto de reivindicaciones sociales, el papel hegemónico de los EEUU fue clave para justificar ideológicamente la polarización de grupos ${ }^{19}$ usando para ello la Doctrina de Seguridad Nacional (DSN), los planes para la eliminación de líderes considerados como "comunistas." Como señalé anteriormente, la DSN tiene una continuidad desde que la política norteamericana declarara los intereses de la región como parte del control geopolítico ejercido a través de la Doctrina Monroe desde principios del siglo XIX. ${ }^{20}$ Desde esta perspectiva, la Guerra Fría fue la justificación ideal para una intervención aún mayor en una región en la que acciones de grupos organizados demandando justicia social, fue convenientemente interpretada como una expresión del comunismo.

Para investigadores en la región como Zea, la DSN brindó el pretexto ideológico necesario para eliminar a la oposición política exigiendo salarios más altos o reforma agraria. Estas demandas amenazaban a las oligarquías y el capital extranjero y multinacional. Como respuesta, el bloque dominante radicalizó los conflictos locales que ya existían desde hacía mucho tiempo.

Esta ideología anticomunista fue adoptada por ejércitos locales imbuidos de valores patrióticos ${ }^{21}$ que se convencieron de una supuesta amenaza comunista para así adaptar las nociones de la seguridad nacional y disfrazar ataques militares contra organizaciones sociales, de estudiantes, de campesinos, maestros, indígenas, sectores de "el pueblo", con demandas étnicas y de clase. Para la sociología latinoamericana, la categoría de "pueblo" es definida como un sujeto político y colectivo analizado incluso antes de la década de 1980.

Así, cuando la cacería anticomunista llegó a las puertas de la región los estados disfrazaron los ataques militares bajo la construcción de mitos de la Guerra Fría (1946-1990), ${ }^{22}$ tales como la teoría de los "dos demonios" y el "enemigo interno" que falsamente promulgaba que el comunismo internacional intentaba implantarse en Chile y Guatemala. Según este mito, "comunistas terroristas" poseían gran armamento, por lo que para restaurar el orden (léase el orden de las oligarquías), debían ser derrotados en el campo de batalla por los estados. El papel de los EEUU y sus agencias (la Central de Inteligencia Nacional, CIA, y la USA-AID, Agencia de Desarrollo Internacional) y pactos de cooperación militar fueron piezas claves en este sentido en la organización militar para llevar a cabo el proyecto imperial, específicamente en proveer de una sofisticada maquinaria de tecnología moderna a los ejércitos nacionales, aparatos de inteligencia, telecomunicaciones, helicópteros, equipos para tortura. Esta maquinaria fue, como ya se ha documentado ampliamente, administrada y ejecutadas por cadenas de mando que operaron desde las instituciones de los estados. ${ }^{23}$ Clave además en diseminar la propaganda anticomunista que

\footnotetext{
${ }_{17}$ Petras, James, Politics and Social Structure..., op. cit., pág. 22.

18 Antes de la Primera Guerra Mundial, pocos trabajadores de la región estaban organizados en sindicatos y grupos de izquierda. Esto cambió dramáticamente con la Gran Depresión, conforme las economías nacionales se volcaban al desarrollo de las industrias locales (política conocida como sustitución de importaciones) lo cual fomentó la migración masiva de campesinos de las áreas rurales hacia los centros urbanos durante la década de 1930, especialmente en Sudamérica. El caso de Brasil ilustra que en 1940 había unos 351.000 trabajadores sindicalizados; para 1947 la cifra había crecido a más del doble, hasta alcanzar los 798.000.

${ }^{19}$ Kuper, Leo, Genocide..., op. cit.

${ }^{20}$ Por lo general, los episodios de extrema violencia siguen midiéndose con el Holocausto durante la segunda guerra mundial. Este sesgo eurocéntrico refuerza una noción sobre el carácter único de la Solución Final. Los estudios de casos paradigmáticos que se repiten en la literatura son además el exterminio de los armenios, el caso de Camboya y las matanzas en Burundi y Ruanda.

${ }^{21}$ Loveman, Brian y Lira, Elizabeth, Politicas de reparación. Chile 1990-2004. Santiago de Chile, LOM Editorial, 2005.

${ }^{22}$ Lemarchand, Rene (ed.), Forgotten Genocides. Oblivion, Denial, and Memory. Pennsylvania, 2011.

${ }^{23}$ Los pactos de integración militar y de desarrollo son conocidos en la década de 1950 como las operaciones de

“Acción Cívica Militar" que traían proyectos paternalistas para paliar la pobreza en áreas rurales principalmente en
} 
construyó mitos para lograr el apoyo de la población a las campañas de exterminio masivo fueron las Operaciones Psicológicas (OPSYC).

¿Qué representaban los grupos de izquierda organizados en términos ideológicos? A la luz de la polarización política, cultural y socio-económica en Latinoamérica, estos grupos, convocados por movimientos populares, reivindicaban demandas de clase y étnicas, representando así una amenaza para los proyectos de un estado antipopular. Esto debido a su capacidad de convocación a sumarse a un proyecto nacional distinto, convirtiéndose así en un importante referente simbólico de resistencia contra el poder militar, la marginalización y la exclusión económica, particularmente en aquellos países con mayoría indígena. De esta forma, la movilización de grupos indígenas en Guatemala en las décadas de 1970-1980 y populares en Chile y Argentina en los años '60 y '70 se convirtió en una amenaza no solo politica, pero también económica y social para la inversión multinacional y transnacional capitalista.

En el Cono Sur, el objetivo de las campañas militares lanzadas contra sectores organizados era eliminar físicamente a una generación de líderes políticos de izquierda, a sus seguidores y simpatizantes, por un lado, así como por otro borrar una memoria cargada de reivindicaciones políticas de gran significado para las luchas sociales en la región. Esta memoria histórica era y continúa siendo, una amenaza para la continuación de las nuevas políticas neoliberales de libre mercado, en un nuevo contexto globalizado. ${ }^{24}$ Ante el temor del éxito de las movilizaciones masivas que podrían obstaculizar la reorganización de la riqueza en la sociedad, las campañas de guerra y terror fueron dirigidas a desarticular al pueblo como fuerza política el cual, como si se tratara de un cáncer, debía ser extirpado quirúrgicamente, para que no lograra reproducirse.

Para justificar los ataques y masacres contra población civil, los estados genocidas aludieron a la teoría de los "dos demonios": un enemigo interno armado capaz de poner en jaque la soberanía y libertad nacional, por un lado, mientras operaciones psicológicas y militares "salvaban" un orden socio-económico político y cultural cristiano-occidental. Historiadores sociales, sin embargo han concluido, con gran acierto, que tal fuerza de la izquierda armada fue exagerada. La evidencia sociológica e histórica sugiere que a menudo los estados identificaron las movilizaciones pacíficas con la subversión. En Argentina, el estado fue más allá de poner en la mira a los guerrilleros montoneros, entre otros, para incluir a los movimientos obreros. También en Guatemala, una Comisión de la Verdad auspiciado por la Naciones Unidas concluyó que el estado exageró la amenaza del "enemigo interno" y la utilizó para criminalizar a la población indígena no combatiente.

Cuando los movimientos populares e indígenas se aliaron con grupos guerrilleros, como sucedió en Guatemala, el estado empleó una estrategia genocida para eliminar las redes de apoyo que brindaron sectores mayas a grupos armados de izquierda a principios de los años '80. Esto se tradujo en la masacre de las Dos Erres en Libertad, Peten: más de 300 campesinos, mujeres y niños fueron víctimas de actos de crueldad, que leerlos invocan escenas surrealistas de terror y sufrimiento. A menudo, soldados de tropa, muchas veces indígenas y pobres, les disparaban a corta de distancia, según expertos forenses. De esta forma, los mitos engendrados por la seguridad nacional justificaron las agresiones de los ejércitos locales contra su propia población, vecinos comunales y compañeros de trabajo. En este sentido las guerras y dictaduras militares poseen un carácter perversamente fratricida.

Chile y Guatemala, por ejemplo ver Barber, William Foster, Internal Security and Military Power: Counterinsurgency and Civic Action in Latin America. Ohio State University Press, 1966. En Bolivia, ver Quintana Taborga, Juan R., Soldados y Ciudadanos: un estudio crítico sobre el servicio militar obligatorio en Bolivia, La Paz, 1998 sobre el programa desarrollista de Acción Cívica. Algunas interrogantes para futuras investigaciones son: ¿Cuáles son las ideologías de la doctrina militar en Latinoamérica en la Post-Guerra Fría? ¿Han cambiado? ¿O continúan basadas en la discriminación y desprecio de lo indígena?

${ }^{24}$ Klein, Naomi, The Shock Doctrine, the Rise of Disaster Capitalism. Picador, 2008. 
Un examen crítico de Latinoamérica a lo largo del siglo XX muestra un siglo casi ininterrumpido de masacres y derramamiento de sangre. Esta larga historia muestra episodios de levantamientos revolucionarios y los consiguientes esfuerzos del estado por aplastarlos. ${ }^{25}$ Como sucedió en Chile en 1907 y con La Violencia en Colombia en la década de los 40, representantes de los estratos más pobres de la sociedad fueron marcados para su eliminación física y simbólica. Al destruir el liderazgo y los cuadros de los grupos de izquierda, de trabajadores, campesinos e indígenas, la violencia extrema erradicó una generación de líderes y con ello las posibilidades de la oposición y la habilidad de organización del pueblo de reconstruir sus redes sociales, las cuales son elementos fundamentales en la preservación de la memoria histórica del grupo como fuerza política.

En Guatemala, el apoyo político y militar de los Estados Unidos fue determinante en la violencia de estado y estrategia de pacificación de las áreas rurales donde el campesinado por razones históricas apoyaba a la guerrilla izquierdista, Unidad Nacional Revolucionaria Guatemalteca (URNG). ${ }^{26}$ Greg Grandin, historiador norteamericano, concluye que Latinoamérica ha sido vital en la creación de Estados Unidos como un Imperio. ${ }^{27}$ Grandin sugiere que los países latinoamericanos han sido usados como un taller de experimento en el que se han orquestado golpes de estado a través de intervenciones militares, donde la tortura, como un mecanismo y práctica del terror y la violencia de estado, fue practicada mucho antes de que el mundo conociera sobre las técnicas de tortura sistemática empleadas en Irak o Afganistán por los soldados norteamericanos. Un ejemplo clásico de intervención militar lo constituye Guatemala donde la administración Eisenhower, a través de la "Operación Success", orquestó en 1954 el derrocamiento del presidente Jacobo Arbenz, democráticamente electo. Este evento histórico dio inicio a la práctica de las desapariciones forzadas en Latinoamérica. Se crearon instituciones que administraron la violencia, se expandieron las bases militares, se redefinieron las técnicas de tortura, a la vez que grupos políticos de obreros y campesinos fueron infiltrados por redes de inteligencia cívico-militar y criminal organizadas.

Para ganar la guerra contra el comunismo en la región, los Estados unidos también han entrenado a los altos mandos militares y escuadrones de la muerte latinoamericanos, donde Francia también ha jugado un papel preponderante. Una de las instituciones estadounidenses más infames que ha entrenado a militares latinoamericanos es el recién rebautizado Instituto del Hemisferio Occidental para la Cooperación en Seguridad (WHISC, por sus siglas en inglés). Aunque su nombre cambió, las prácticas son las mismas, y activistas de derechos humanos

\footnotetext{
${ }^{25}$ En Chile, a finales de la década de 1890, un grupo de mineros que extraían nitrato de sodio se negaron a deponer una huelga, por lo que fueron acribillados por tropas estatales, como lo documenta Lessie Jo Frazier en su obra Salt in the Sand. Otros ejemplos se dan en Argentina, El Salvador y Colombia. En 1919 en Argentina, el descontento laboral fue reprimido sangrientamente por el ejército, en el episodio conocido como la "Semana Trágica." En El Salvador, la violencia contra grupos organizados cobró la vida de alrededor de 30.000 personas en una matanza de campesinos e indígenas organizados alrededor del líder comunista Agustín Farabundo Martí en 1932. En otro ejemplo en Trujillo, Perú, el levantamiento de la APRA (Alianza Popular Revolucionaria Americana) y las brutales represalias del ejército en 1931 iniciaron un largo período de violencia política en el país. En Colombia en 1940, "La Violencia" arrojó a los campesinos conservadores y liberales a una guerra civil donde pereció un cuarto de millón de personas, de una población de diez millones. La revolución mexicana dirigida por Emiliano Zapata en 1910 es otro ejemplo de las luchas por remediar la estratificación de las sociedades basadas en la acumulación de tierras.

26 De acuerdo al Comité de Unidad Campesina (CUC), que surgió a través de un proceso de concientización del campesinado antes del genocidio (1981-1983), y que fue duramente golpeado: "Las ideas marxistas se encontraron, complementaron y enriquecieron mutuamente con el pensamiento y la cosmovisión maya dual, basada en el respeto a la Madre Naturaleza, el arte de la guerra aplicada a la guerra de guerrillas y al caudal de experiencias de resistencia de los pueblos indígenas, lo que trajo como resultado una profunda mística revolucionaria. En este contexto revolucionario, las comunidades Poptí, Chuj, Ixil, K’iche’, Quekchí, Mam y otras, registran en su memoria histórica la decisión de sus autoridades tradicionales, de incorporarse de manera colectiva y comunitaria al Proyecto Revolucionario", en línea en http://www.cuc.org.gt/materiales/historiadeguatemala.pdf, consulta12 de septiembre de 2013.

${ }^{27}$ Hobsbawm, Eric, The Age of Empire (1875-1914), New York, Vintage Group, 1989 y On Empire: America, War, and Global Supremacy, New York, Pantheon Books, 2008.
} 
continúan refiriéndose a la institución como antes: la Escuela de las Américas (SOA, por sus siglas en inglés), localizado en la Base Militar Fort Benning en Columbus, Georgia.

\section{Legados: construccion de silencios colectivos y pactos}

Daniel Feierstein sugiere que el terror infundido a través de la desaparición forzada, tortura, campos de exterminio y abusos sexuales afectaron no sólo a las víctimas sino que además penetraron en el conjunto social y como tal tuvieron como función modificar las relaciones sociales. Feierstein elabora así una teoría que incluye el análisis sobre los legados que perduran en la postguerra. ${ }^{28}$

A partir de la post-Guerra Fría, estudios sobre la significación, la temporalidad y los esfuerzos por la memoria histórica en la región se han multiplicado. ${ }^{29}$ Desde esta perspectiva, una memoria histórica de reivindicaciones políticas sólo puede transmitirse y recuperarse en relación a otros individuos que han compartido experiencias similares porque, como sugiere el célebre sociólogo francés Maurice Halbwachs, la memoria es un proceso colectivo.

Estos grupos de izquierda se identificaban con un repertorio de prácticas sociales enmarcados por la movilización de los movimientos sociales. Este baúl de memoria colectiva incluía: las ideologías obreras del poder popular, las huelgas, la toma de edificios, los mítines, las manifestaciones callejeras, los comedores comunitarios, música, poesía, teatro, arte, artesanías populares, y los aniversarios de eventos significativos. ${ }^{30}$ Integrados todos como parte de la memoria histórica, estos referentes nemónicos han servido para movilizar grupos políticos que exigen la eliminación de las grandes desigualdades, y condiciones de vida casi feudales de grandes segmentos de la población latinoamericana, en especial allí donde los pueblos indígenas constituyen la gran mayoría. ${ }^{31}$

Pocos estudios, sin embargo se han enfocado en a la construcción de silencios colectivos que esconden el papel de las ideologías en fomentar y justificar la violencia de estado, y de que forma la mitología de la Guerra Fría se mantiene en la postguerra. Estos silencios son construidos a partir del miedo colectivo de caer víctimas del terrorismo de estado, pero también de complicidades cívico-militares que resguardan los secretos de los crímenes. Estos pactos de silencio, un acuerdo no escrito en el caso de Chile por ejemplo, también refuerzan la cultura militar y sus valores (como la disciplina y la lealtad) que permanece casi intacta a través del tiempo.

\footnotetext{
${ }^{28}$ Rafael Lemkin, uno de los fundadores de los estudios del genocidio, llegó a la conclusión de que la violencia podía definirse como genocida en la medida en la que fuera planificada para erradicar características esenciales del grupo victimizado: "El genocidio no necesariamente implica la destrucción inmediata de una nación. Su intención... es la destrucción de los cimientos esenciales de la vida de grupos nacionales, con el fin de aniquilar a los grupos mismos". Objeto de encendidas controversias, no obstante, sigue siendo la definición de lo que de hecho constituye un grupo. 29 Piper, Isabel, Obstinaciones de la memoria: la dictadura militar chilena en las tramas del recuerdo, Tesis doctoral, Departamento de Psicología Social, Universidad Autónoma de Barcelona, 2005; Marchesi, Aldo, "Vencedores vencidos: las respuestas militares frente a los informes 'Nunca Más' en el cono sur”, en Hershbert, Eric y Agüero, Felipe (comps.), Memorias militares sobre la represión en el Cono Sur: Visiones en disputa en dictadura y Democracia. Madrid, Siglo XXI, 2005; Hite, Katherine y Cesarini, Paola (eds.), Authoritarian Legacies and Democracy in Latin America and Southern Europe. Indiana, The University of Notre Dame Press, 2004.

${ }^{30}$ Enfocándose en la transmisión de rituales y prácticas culturales, Halbwachs estudió la transformación de clases en Europa y argumentó que cada clase social se suscribe a una memoria colectiva particular construida a lo largo de extensos períodos. Cada grupo de clase es heredero de una conciencia política particular, un reservorio de eventos, ideologías y prácticas culturales de grupos pasados -la encarnación de los "marcos de la memoria".

${ }^{31}$ Leslie Gill ha indicado que "las demandas a favor de mejores condiciones de vida constituyen para los militares la evidencia de la propensión innata de la gente campesina, indígena y de clase obrera hacia la violencia y la ingobernabilidad". Ver Gill, Leslie, The School of the Americas: Military Training and Political Violence in the Americas (American Encounters/Global Interactions), Dunham, Duke University Press, 2004.
} 
En Mirrors of Destruction, War Genocide y Modern Identity, Omer Bartov sugiere que un análisis de estos procesos debe también incluir el estudio de las secuelas simbólicas, como la militarización. Considerando el Holocausto como caso de estudio, Bartov sugiere que:

"la Alemania Nazi inventó «la glorificación del sistema industrial de asesinar civiles» cuyo legado su legado se materializa o por ejemplo en la representación de «culpabilidad como honor, atrocidad como heroísmo, y genocidio como redención» que persigue a la civilización incluso mucho después del Nazismo". ${ }^{32}$

Más aún, Bartov señala que las sociedades europeas que emergieron tras la Segunda Guerra Mundial sufrían de un trauma colectivo como resultado de las atrocidades cometidas contra los judíos. El horror de los campos de concentración, las chimeneas de gas, el hambre, las deportaciones, el exilio y la colaboración del régimen de Vichy en Francia con Alemania, trastocaron las identidades al exaltar la violencia, la valoración de sentimientos nacionalistas y practicar la deshumanización extrema. El planteamiento de Bartov nos muestra un camino para el análisis histórico y sociológico sobre las secuelas de la Guerra Fría y las identidades colectivas que emergieron tras su colapso.

En la post-Guerra Fría estos mitos fueron reencarnados o reemplazados por otros mitos, contribuyendo así a esconder atrocidades y a la formación de silencios colectivos y pactos de silencio. ${ }^{33}$ Estos silencios sociales han limitado el acceso a aspectos claves de la cultura militar tales como el silencio-complicidad, la disciplina y la lealtad con mandos superiores y entre el grupo. Este código de silencio refuerza una versión parcelada de la realidad o una "casi verdad" del pasado y del presente, la cual no nos permite cuestionar, por ejemplo, la construcción social y militar del torturador, o del agente civil-militar que facilitó la identificación de las víctimas para su posterior ejecución con la más completa impunidad. Como mis investigaciones demuestran, los silencios impiden conocer la relación de dependencia y de explotación que mantiene el ejército guatemalteco en las áreas rurales, aun después de la guerra (1960-1996).

La ausencia de debates críticos sobre el papel de la justicia transicional ${ }^{34}$ en silenciar la continuación de proyectos enmarcados dentro del colonialismo interno mantenido por la oligarquía y ejército durante y después de la guerra en Guatemala, por ejemplo, afectando a la población indígena campesina, que oscila entre el 60 y el $80 \%$ de la población, no toman en cuenta cómo ideologías anticomunistas, por ejemplo, continúan perpetuándose incluso después de la firma de la paz como en Guatemala, o elecciones democráticas como en Chile. ${ }^{35}$ Mientras que en Colombia, que sufre el conflicto armado de la mayor duración del hemisferio, y en las naciones centroamericanas, el legado de los conflictos armados perdura a pesar de los esfuerzos enmarcados dentro de los procesos de la "justicia transicional," que promueven la reconciliación y la paz.

\footnotetext{
32 Bartov, Omar, Mirrors of Destruction, War Genocide y Modern Identity, Oxford University Press, 2000, págs. 29-30.

${ }_{33}$ Esparza, Marcia, "Courageous Soldiers (valientes soldados): Politics of Concealment in the Aftermath of State Violence in Chile", en Esparza, Marcia et al., State Violence and Genocide in Latin America, op. cit.

${ }^{34} \mathrm{~A}$ partir de estudios de genocidio y postcoloniales, mi objetivo como socióloga es sugerir que a pesar de los logros de la comisión de la verdad, esta no reveló el sistema de silencios construidos y que esconden lo que el historiador Francés René Lemarchand (Forgotten Genocides..., op. cit.) denomina como las "verdades incómodas" de las guerras. Así como la memoria es social, también lo son los silencios construidos para esconder las raíces, por ejemplo de los mitos de la Guerra Fría.

${ }^{35}$ En mi trabajo de investigación de la post-guerra en Guatemala (Esparza, Marcia, "Post-war Guatemala: Long term effects of psychological and ideological militarization of the K'iche Mayans", Journal of Genocide Research 7 (3), 2005) sostengo que la posibilidad de la elaboración de una memoria colectiva reivindicadora por parte de grupos colonizados mayas es muchas veces suprimida por la militarización y el militarismo, o el aspecto ideológico del control militar.
} 
Aún quedan muchas áreas de investigación a profundizar. Una de ellos es el estudio de los "rescatistas", analizados empíricamente durante la Shoab. ${ }^{36}$ ¿Cómo puede este conocimiento fomentar la comprensión de actos de extrema valentía, de heroísmo ${ }^{37}$ en la región? ¿Por qué el estudio de los "Justos" en América Latina ha sido en gran medida excluido de la academia y cómo el rompimiento de este silencio puede añadir al estudio del legado de atrocidades en masa? ¿Cómo la ausencia de un análisis crítico de las forma de rescate contradice o complementa la cultura del miedo que prevalece en la región? ¿Cuáles, si las hay, son las similitudes entre las identidades de los grupos políticos, sociales y culturales a los que pertenece el socorrista? Estos interrogantes son ahora tarea de las nuevas generaciones de cientistas sociales y humanistas para seguir construyendo conocimiento sobre procesos y legados genocidas, así como las características de sociedades más humanas y altruistas.

\section{Bibliografía}

Águila, Gabriela, Dictadura, represión y sociedad en Rosario, 1976-1983: Un estudio sobre la represión y los comportamientos y actitudes sociales en dictadura. Buenos Aires, Prometeo, 2008.

Bartov, Omar, Mirrors of Destruction, War Genocide y Modern Identity. Oxford University Press, 2000.

Casiro, Jessica, "Argentine Rescuers: a Study on the "Banality of Good»", Journal of Genocide Research, 8:4, 2006.

Cesaire, Aime de, Discourse on Colonialism. New York, Monthly Review Press, 2000.

Cockcroft, James, Neighbors in Turnmoil. New York, Harper \& Rows Publishers, 1989.

Esparza, Marcia, "Post-war Guatemala: Long term effects of psychological and ideological militarization of the K'iche Mayans", Journal of Genocide Research 7 (3), 2005.

Esparza, Marcia, "Courageous Soldiers (valientes soldados): Politics of Concealment in the Aftermath of State Violence in Chile", en Esparza, Marcia et al., State Violence and Genocide in Latin America, London, Routledge Critical Terrorism Studies, 2010.

Esparza, Marcia; Huttenbach, Henry y Feierstein, Daniel (eds.), State Violence and Genocide in Latin America. London, Routledge: Critical Terrorism Studies, 2010.

Fanon, Franz, Los Condenados de la Tierra, 2008.

Feierstein, Daniel, El genocidio como práctica social. Entre el nazismo y la experiencia argentina. Buenos Aires, Fondo de Cultura Económica, 2007.

Feierstein, Daniel, Seis Estudios sobre Genocidio. Análisis de relaciones sociales: otredad, exclusión, exterminio. Buenos Aires, EUDEBA, 2000.

Frazier, Lessie Jo, Salt in the Sand: Memory, Violence, and the Nation State in Chile, 1890 to the Present. Durham, Duke University Press, 2007.

García Ferreira, Roberto (comp.), Guatemala y la Guerra Fría en América Latina 1947-1977. Guatemala, Centro de Estudios Urbanos y Regionales de Universidad de San Carlos, 2010.

Gill, Leslie, The School of the Americas: Military Training and Political Violence in the Americas (American Encounters/Global Interactions). Dunham, Duke University Press, 2004.

\footnotetext{
36 Ver por ejemplo el trabajo de Casiro, Jessica, "Argentine Rescuers: a Study on the "Banality of Good", Journal of Genocide Research, 8:4, 437-454, 2006.

37 Todorov, Tzvetan, The Fragility of Goodness: Why Bulgaria's Jews Survived the Holocaust. London, Weindenfeld \& Nicolson, 2001.
} 
Gómez-Suárez, Andrei, "US-Colombian relations in the 1980s: political violence and the onset of the Unión Patriótica genocide", en Esparza, Marcia et al., State Violence and Genocide in Latin America. London, Routledge: Critical Terrorism Studies, 2010.

González Casanova, Pablo, “Colonialismo Interno, Una Redefinición”, en Borón, Atilio (comp.), La teoría marxista hoy: problemas y perspectivas. Buenos Aires, CLACSO, 2006, en línea en http://biblioteca.clacso.edu.ar/ar/libros/campus/marxis/P4C2Casanova.pdf, consulta 6 de marzo de 2013.

Grandin, Greg, Empire's Workshop: Latin America, the United States and the Rise of the New Imperialism. New York, Metropolitan Books, 2006.

Halbwachs, Maurice, On Collective Memory. Chicago, The University of Chicago Press, 1992.

Hite, Katherine y Cesarini, Paola (comps.), Authoritarian Legacies and Democracy in Latin America and Southern Europe. The University of Notre Dame Press, 2004.

Hobsbawm, Eric, The Age of Empire. 1875-1914. New York, First Vintage Books, 1989.

Hobsbawm, Eric, On Empire: America, War, and Global Supremacy, New York, Pantheon Books, 2008.

Joseph, Gilbert M. (Ed.), In from the Cold, Latin America's New Encounter with the Cold War. Durham, Duke University Press, 2007.

Klein, Naomi, The Shock Doctrine, the Rise of Disaster Capitalism. Picador, 2008.

Kuper, Leo, Genocide: Its Political Use in the Twentieth Century. New Haven, Yale University Press, 1981.

Lemarchand, Rene (ed.), Forgotten Genocides. Oblivion, Denial, and Memory. Pennsylvania, 2011.

Loveman, Brian \& Lira, Elizabeth, Politicas de reparación. Chile 1990-2004. Chile, LOM Editorial, 2005.

Marchesi, Aldo, 'Vencedores vencidos: las respuestas militares frente a los informes 'Nunca Más' en el cono sur", en Hershbert, Eric y Agüero, Felipe (comps.), Memorias militares sobre la represión en el Cono Sur: Visiones en disputa en dictadura y democracia, Madrid, Siglo XXI, 2005.

Mariátegui, José Carlos, Siete Ensayos de Interpretación de la Realidad Peruana. Caracas, Fundación Biblioteca Ayacucho, 2007.

McSherry, Patrice, Los estados depredadores. Chile, LOM, 2009.

Memmi, Albert, The Colonizer and the Colonized. Boston, Beacon Press, 1991.

Mignolo, Walter, The Darker Side of Western Modernity: Global Futures, Decolonial Options (Latin America Otherwise). Durham, Duke University Press, 2011.

Pereira, Víctor, Unfinished Conquest: the Guatemalan Tragedy. California, University of California Press, 1993.

Petras, James, Politics and Social Structure in Latin America. New York, Monthly Review Press, 1970.

Piper, Isabel. Obstinaciones de la memoria: la dictadura militar chilena en las tramas del recuerdo, Tesis doctoral, Departamento de Psicología Social, Universidad Autónoma de Barcelona, 2005.

Quijano, Alberto, "The Coloniality of Power, Eurocentrism and LatinAmerica", en Neplanta. Views from South 1. 3., Duke University Press, 2000, en línea en http://www.unc.edu/ aescobar/wan/wanquijano.pdf, consulta 6 de marzo de 2013.

Quintana Taborga, Juan R., Soldados y Ciudadanos: un estudio crítico sobre el servicio militar obligatorio en Bolivia, La Paz, 1998. 
Robin, Marie-Monique, Escuadrones de la Muerte. La Escuela Francesa. Buenos Aires, Sudamericana, 2005.

Salvi, Valentina, "De Vencedores a víctimas: 25 años de memoria castrense", en Temas y Debates $\mathrm{N}^{\circ}$ 17, Rosario, 2009.

Spenser, Daniela (comp.), Espejos de la guerra fría. México, CIESAS-Porrúa, 2004.

Spivak, Gayatri, In Other Worlds: Essays in Cultural Politics. New York, Methuen, 1987.

Todorov, Tzvetan, La Conquista de América: la Cuestion del Otro (Conquest of America: the Question of the Other). 1984.

Todorov, Tzvetan, The Fragility of Goodness: Why Bulgaria's Jews Survived the Holocaust. London, Weindenfeld \& Nicolson, 2001.

Vasconcelos, Maribel, La Guerra Fría. Tesis de Maestría, Instituto de Investigaciones Dr. José María Luis Mora, 2012.

Young, Robert C. J., Postcolonialism: An Historical Introduction. Oxford, Blackwell Publishers, 2001.

Zea, Leopoldo, América como conciencia. México, UNAM, 1972. 